A. Nilson Quezado Cavalcante * e Etienne F. Cracco**

\title{
Os incentivos às exportações de manufaturados: análise e sugestão
}

1. Resultados do programa governamental. 2. Descriçăo dos incentivos. 3. 0 impacto dos incentivos nas exportacões. 4. Reaçōes das emprésas. 5. Uma solução: uma companhia de exportação.
Nos últimos cinco anos, o Govêrno federal tem pôsto em prática uma política de incentivos às exportações de produtos manufaturados. De um modo geral, êste programa tem sido bem sucedido. No entanto, uma análise cuidadosa dos efeitos prováveis dos diversos incentivos nas variáveis que influenciam as exportaçōes poderia evidenciar graves deficiências na atual política. 0 objetivo dêste artigo é proceder a essa análise bem como recomendar uma solução integrada que deverá corrigír as falhas do referido programa.

\section{RESULTADOS DO PROGRAMA GOVERNAMENTAL}

Sob o impacto dos incentivos oficiais, as exportações brasileiras de produtos manufaturados têm crescido significativamente nos últimos anos, como mostra o quadro 1 . A sua participação no valor total das exportações cresceu de 8,7\% em 1966 para 16,8\% em 1970. A taxa de aumento com relação ao ano anterior foi de $40 \%$ em 1969 e $60 \%$ em 1970 , aproximadamente. ${ }^{1}$
QUADRO 1. Exportações brasileiras de manufaturas 1966-1970

\begin{tabular}{ccc}
\hline Ano & $\begin{array}{c}\text { Valor } \\
\text { (US\$ 1.000) }\end{array}$ & $\begin{array}{c}\text { \% sôbre } \\
\text { exportaçöes } \\
\text { totais }\end{array}$ \\
\hline 1966 & 151.418 & 8,7 \\
1967 & 202.532 & 12,2 \\
1968 & 201.043 & 10,7 \\
1969 & 283.174 & 12,3 \\
1970 & $454.910^{*}$ & $16,8^{*}$ \\
\hline
\end{tabular}

Fonte: CACEX

* Dados proviśrios.

A maior parte dessas exportaçōes destina-se à Associação Latino-Americana de Livre Comércio (ALALC) e aos

* Professor-assistente do Departamento de Economia da Escola de Adminstracão de Emprêsas de São Paulo da Fundaçåo Getulio Vargas.

** O Sr. Etienne F. Cracco está concluindo sua tese de doutoramento para a Michigan State University (EUA).

Os autores agradecem, entre outras, a colaboracso de Robert N. V. C. Nicol e colaboraçattos Filho A responsabilidade Ary aos autores.

1 Além dos incentivos, o sistema cambial de "taxa flexível" (pósto em prática a partir de 1968) muito contribuiu para o aumento das exportaçбes. No sistema anterior, havia uma acentuada defasagem entre a elevacăo dos custos internos, resultante da inflaço $a$ reajuste da taxa de cambio, desencorajando assim as exportaçbes. 
Estados Unidos (ver quadro 2). Estas áreas absorveram, em $1969,38,4 \%$ e $27,7 \%$, respectivamente, das nossas exportações de manufaturados. O Mercado Comum Europeu (MCE) e a Associação Européia de Livre Comércio (AELC)

vieram em seguida, com 19,2 e $5,9 \%$, respectivamente. E interessante observar que, nos últimos anos, os percentuais referentes à ALALC e MCE têm aumentado, enquanto $o$ dos Estados Unidos tem decrescido.

QUADRO 2. Exportação

brasileira de manufaturados por mercados

1967-1969

\begin{tabular}{|c|c|c|c|c|c|c|}
\hline \multirow{2}{*}{ Discriminação } & \multicolumn{2}{|l|}{1967} & \multicolumn{2}{|l|}{1968} & \multicolumn{2}{|l|}{1969} \\
\hline & $(\mathrm{US} \$ 1.000)$ & $\begin{array}{l}\% \text { s' } \\
\text { total }\end{array}$ & (US\$ 1.000) & $\begin{array}{ll}\% & \mathrm{~s} / \\
\text { total }\end{array}$ & $(\mathrm{US} \$ 1.000)$ & $\begin{array}{ll}\% & s / \\
\text { total }\end{array}$ \\
\hline $\begin{array}{l}\text { ALALC } \\
\text { EUA } \\
\text { MCE } \\
\text { AELC } \\
\text { Outros }\end{array}$ & $\begin{array}{r}69.639 \\
75.369 \\
25.164 \\
9.221 \\
29.813\end{array}$ & $\begin{array}{r}33,3 \\
36,0 \\
12,0 \\
4,4 \\
14,3\end{array}$ & $\begin{array}{r}73.923 \\
71.312 \\
29.128 \\
11.990 \\
17.738\end{array}$ & $\begin{array}{r}36,2 \\
34,9 \\
14,3 \\
5,9 \\
8,7\end{array}$ & $\begin{array}{r}110.555 \\
79.815 \\
55.142 \\
16.923 \\
25.367\end{array}$ & $\begin{array}{r}38,4 \\
27,7 \\
19,2 \\
5,9 \\
8,8\end{array}$ \\
\hline Total & 209.206 & 100,0 & 204.091 & 100,0 & 287.802 & 100,0 \\
\hline
\end{tabular}

Fonte: CACEX.

Obs.: Há pequenas discrepâncias entre êstes totais e os dados do quadro 1.

\section{DESCRIÇÃO DOS INCENTIVOS}

Podemos classificar os incentivos às exportações de produtos industrializados em três categorias: fiscais, financeiros e outros. Apresentaremos uma descrição suscinta dos diversos incentivos em cada uma dessas categorias. ${ }^{2}$

\subsection{Incentivos fiscais}

Estes incentivos consistem, essencialmente, na isenção ou redução de impostos para os produtos manufaturados destinados à exportação.

\subsubsection{Isenção do impôsto de renda}

Os lucros obtidos na exportação de manufaturados são isentos dêsse impôsto, cuja alíquota é de $30 \%$ para os lucros não distribuídos.

\subsubsection{Dedução das despesas} com a promoção de exportações

Para efeito de impôsto de renda, as emprêsas industriais podem deduzir de seu lucro tributável as seguintes despesas relacionadas com a exportação de manufaturas: a) com a promoção e propaganda de seus produtos no exterior; b) com a participação em feiras $e$ exposições internacionais; c) com a manutenção de filiais, escritórios e depósitos no exterior.

\subsubsection{Redução do impôsto} sôbre as transferências financeiras para o exterior

Está prevista a redução ou restituição do impôsto de renda incidente sôbre as transferências financeiras para 0 exterior, correspondentes ao pagamento de royalties, assistência técnica e juros, relacionadas com a produção de manufaturas para exportação, desde que essas operações sejam registradas no Banco Central.

\subsubsection{Isenção do IPI}

As exportações de manufaturas são isentas do Impôsto sôbre Produtos Industrializados (IPI). As alíquotas dêste impôsto, para a maioria dos produtos exportáveis, situam-se entre 12 e $24 \%$. A isenção estende-se às vendas internas a residentes de países estrangeiros mediante pagamento em cheques de viagem e também às vendas internas pagas em cruzeiros resultantes da conversão de divisas oriundas de financiamento externo, a longo prazo, de instituições financeiras internacionais ou govêrno de outros países. Como - IPI incide apenas sôbre o valor adicionado, as emprêsas industriais podem creditar-se do impôsto pago anteriormente sôbre os produtos intermediários utilizados em suas manufaturas para exportação. Este crédito, que equivale a um subsídio, pode ser utilizado para o pagamento do IPI relativo às vendas internas da emprêsa beneficiada, de emprêsas coligadas a essa emprêsa ou que Ihe forneçam insumos.

\subsubsection{Isenção do ICM}

A alíquota do Impôsto sôbre Circulação de Mercadorias (ICM), impôsto estadual, é normalmente de $14,5 \%$. As exportações de manufaturados estão isentas dêsse impôsto. Tal benefício estende-se às vendas internas pagas em cruzeiros resultantes da conversão de divisas provenientes de financiamento a longo prazo de instituições oficiais estrangeiras. $O$ sistema de crédito fiscal, descrito no item anterior, aplica-se também ao ICM.

\subsubsection{Importação de bens de capital livres de impostos}

São isentas do IPI e tarifas aduaneiras as importações de bens de capital destinados à produção de manufaturas, desde que não haja similares nacionais.

\footnotetext{
2 Para uma descrição mais completa, ver o Manual do exportador, publicação da CACEX, Banco do Brasil S. A. Convém advertir que, como êste artigo foi escrito em dezembro de 1970, não incorpora as modificaçōes do sistema de incentivos realizadas após aquêle período.
} 


\subsubsection{Drawback}

As tarifas aduaneiras pagas sôbre bens intermediários utilizados na produção destinada à exportação são devolvidas às emprêsas, total ou parcialmente. Essas tarifas variam, geralmente, de 15 a $55 \%$. Esse incentivo aplica-se também às vendas internas pagas em cruzeiros resultantes da conversão de um financiamento internacional a longo prazo, concedido por organismos oficiais. Qualquer importação sob o regime de drawback é também isenta do IPI.

\subsubsection{Isenção do impôsto} sôbre operações financeiras

As taxas dêste tributo variam de 0,5 a $1,0 \%$. A isenção aplica-se às operações de cẩmbio, seguro e crédito, relativas a exportações de manufaturados.

2.1.9 Isenção do impôsto sôbre lubrificantes, combustíveis e energia elétrica

Este tributo é federal e aplica-se aos produtos mencionados, que estão isentos do ICM (estadual). Esse incentivo beneficia as indústrias que utilizam os referidos insumos em produtos para exportação, bem como os navios nacionais ou fretados com prerrogativas de bandeira brasileira.

\subsubsection{Isenção de outros} tributos, taxas, quotas, etc.

As exportações brasileiras eram oneradas por uma série de taxas, impostos, quotas, etc. Todos foram eliminados, permanecendo apenas as taxas referentes à efetiva prestação de serviço e às contribuições à previdência social.

\subsection{Incentivos financeiros}

Os incentivos desta categoria consistem na oferta de linhas de crédito especiais, a juros mais baixos do que os normalmente cobrados pelos bancos comerciais.
2.2.1 Financiamento à produção pelos bancos comerciais

O Banco Central oferece redescontos especiais à taxa de $4 \%$ ao ano aos bancos comerciais, para que êstes concedam empréstimos às emprêsas industriais que realizam exportações, a taxas que não ultrapassem $8 \%$ ao ano (incluindo comissões) e por períodos que não excedam um ano. A importância dêste incentivo fica patente, quando se considera que a taxa de inflação em nosso País tem sido, nos últimos três anos, da ordem de $20 \%$ ao ano, sendo a taxa de juros normalmente cobrada pelos bancos particulares superior a $24 \%$.

\subsubsection{Financiamento à produção pelo Banco do Brasil}

A Carteira de Crédito Agrícola e Industrial dêsse Banco fornece crédito para complementação de capital de giro das emprêsas que se comprometam a elevar sua produção de manufaturas para exportação. Os juros são de $12 \%$ ao ano mais correção monetária.

\subsubsection{Financiamento à} produção pelo Banco Nacional de Desenvolvimento Econômico

Semelhante ao item anterior.

\subsubsection{Financiamento à exportação}

Êsses empréstimos são concedidos diretamente pela Carteira de Comércio Exterior (CACEX) para financiar as seguinte operações: a) exportações (normais ou em consignação) de bens de capital ou de consumo duráveis; b) venda no exterior de estudos e projetos técnico-econômicos $e$ de engenharia; c) programas de promoção e comercialização de nossos produtos no exterior. A taxa de juros acompanha a estabelecida entre exportador e importador, não podendo ser inferior a $7 \%$ ao ano.

\subsubsection{Seguro de crédito à exportação}

Este seguro cobre os riscos normais do comércio internacional: riscos comerciais (como a insolvência do importador) e riscos políticos e extraordinários. São

beneficiários as entidades de crédito que financiam a exportação e os próprios exportadores.

\subsection{Outros incentivos}

Os incentivos dessa categoria consistem, principalmente, na eliminação ou simplificação de trâmites burocráticos bem como nas atividades dos órgãos de informação e promoção no campo do comércio externo.

\subsubsection{Exportações em consignação}

Admite-se a remessa de vários produtos manufaturados em consignação ao exterior. Caso a venda seja efetuada, a operação passa a ser uma exportação normal. Caso contrário, a mercadoria pode retornar ao País sem cobertura cambial.

\subsubsection{Remessa de amostras sem formalidades}

Os exportadores efetivos e em potencial podem remeter amostras e pequenas encomendas ao exterior, até o limite de US $\$ 100.00$, sem guia de exportação ou qualquer tråmite burocrático.

\subsubsection{Exportações sem} formalidades nas zonas de fronteiras

Essas operações precisam ser realizadas nas cidades fronteiriças e estão sujeitas a limites quanto ao valor e natureza do produto. 0 pagamento pode ser feito em cruzeiros, dispensando

formalidades cambiais.

2.3.4 Garantia a participantes em concorrências internacionais 
Essa garantia é prestada pelo Banco Nacional do Desenvolvimento Econômico (BNDE) a emprêsas nacionais dentro dos seguintes limites: mínimos - US $\$ 200$ mil; máximo - US\$ 5 milhões. A firma beneficiada precisa satisfazer certas condições e pagar as despesas necessárias bem como uma taxa de 0,5 a $2 \%$ da importância garantida.

\subsubsection{Serviços da CACEX}

Esste departamento publica um boletim que relaciona oportunidades comerciais para produtos brasileiros no exterior, além de fornecer outras informações de interêsse para os exportadores. A CACEX possui ainda um fichário de exportadores, para os quais remete informações sôbre oportunidades para seus produtos especificos.

\subsubsection{Serviços consulares}

Os consulados e escritórios comerciais do Brasil obtêm e divulgam informações de interêsse comercial para o nosso País e dão assistência às emprêsas estrangeiras que desejam importar do Brasil. Além disso, colaboram para a participação do nosso País em feiras e exposições internacionais.

\section{O IMPACTO DOS INCENTIVOS NAS EXPORTAÇOES}

Para analisar a eficácia dos incentivos, desenvolvemos no quadro 3 a matriz que apresenta o efeito provável de cada incentivo nas principais variáveis que afetam a oferta e a demanda externa de manufaturados produzidos no Brasil. Essas variáveis são as seguintes: insumos, produção, preço, produto (tipo, qualidade, forma de apresentação), promoção e distribuição. Cada efeito foi classificado, em função de sua intensidade, em "fraco", "médio" ou "forte". É necessário salientar que essa classificação é apriorística e, portanto, passivel de refutação em bases empíricas. Passamos agora a avaliar a eficácia dos diversos incentivos, levando em conta, principalmente, a matriz apresentada no quadro 3.

\section{QUADRO 3. Efeitos dos}

incentivos à exportação

\begin{tabular}{|c|c|c|c|c|c|c|c|}
\hline \multicolumn{2}{|r|}{ Incentivos } & $\begin{array}{c}\text { Insu- } \\
\text { mos }\end{array}$ & $\begin{array}{l}\text { Pro- } \\
\text { dução }\end{array}$ & Preço & $\begin{array}{l}\text { Pro- } \\
\text { duto }\end{array}$ & $\begin{array}{l}\text { Pro- } \\
\text { moção }\end{array}$ & $\begin{array}{l}\text { Distri- } \\
\text { buição }\end{array}$ \\
\hline 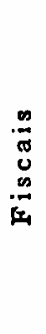 & $\begin{array}{l}\text { 1. Isenção do impôsto de renda } \\
\text { 2. Dedução das despesas com a promoção de exportações } \\
\text { 3. Redução do impósto s/transf. financ. p/exterior } \\
\text { 4. Isenção do IPI } \\
\text { 5. Isenção do ICM } \\
\text { 6. Importação de bens de capital livres de impostos } \\
\text { 7. Drawback } \\
\text { 8. Isenção do impôsto sôbre operações financeiras } \\
\text { 9. Isenção do impôsto sôbre lubrificantes, combustiveis, } \\
\text { e energia elétrica } \\
\text { 10. Isençâo de outros tributos, taxas, quotas, etc }\end{array}$ & $\begin{array}{l}\text { forte } \\
\text { forte } \\
\text { fraco* } \\
\text { fraco }\end{array}$ & $\begin{array}{l}\text { médio } \\
\text { fraco } \\
\text { forte } \\
\text { forte } \\
\text { médio } \\
\text { forte } \\
\text { medio } \\
\text { fraco }\end{array}$ & $\begin{array}{l}\text { médio } \\
\text { forte } \\
\text { forte } \\
\text { fraco } \\
\text { forte } \\
\text { fraco } \\
\text { fraco } \\
\text { fraco }\end{array}$ & $\begin{array}{l}\text { fraco } \\
\text { fraco } \\
\text { médio }\end{array}$ & médio & $\begin{array}{l}\text { fraco } \\
\text { fraco } \\
\text { fraco }\end{array}$ \\
\hline 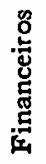 & $\begin{array}{l}\text { 1. Financiamento à produção pelos bancos comerciais } \\
\text { 2. Financiamento à produção pelo Banco do Brasil } \\
\text { 3. Financiamento à produção pelo BNDE } \\
\text { 4. Financiamento à exportação } \\
\text { 5. Seguro de crédito à exportação }\end{array}$ & $\begin{array}{l}\text { forte* } \\
\text { forte* } \\
\text { forte* } \\
\text { forte* }\end{array}$ & $\begin{array}{l}\text { forte } \\
\text { médio } \\
\text { médio } \\
\text { médio }\end{array}$ & $\begin{array}{l}\text { forte } \\
\text { médio } \\
\text { médio } \\
\text { forte } \\
\text { fraco }\end{array}$ & & $\begin{array}{l}\text { médio } \\
\text { médio }\end{array}$ & \\
\hline 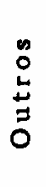 & $\begin{array}{l}\text { 1. Exportaçōes em consignação } \\
\text { 2. Remessa de amostras sem formalidades } \\
\text { 3. Exportaçóes sem formalidades nas zonas de fronteiras } \\
\text { 4. Garantia a participantes em concorrências internacionais } \\
\text { 5. Serviços da CACEX } \\
\text { 6. Serviços consulares }\end{array}$ & & forte & fraco & & $\begin{array}{l}\text { médio } \\
\text { fraco } \\
\text { forte } \\
\text { médio } \\
\text { fraco }\end{array}$ & $\begin{array}{l}\text { fraco } \\
\text { médio }\end{array}$ \\
\hline
\end{tabular}

* Considerando-se o capital de giro um insumo.

\subsection{Incentivos fiscais}

As variáveis mais afetadas por êsses incentivos são a produção e o preço. 0 efeito no produto, promoção e distribuição, é, com com poucas exceções, inexistente.

Com relação à isenção do IPI — como as alíquotas variam na razão inversa da essencialidade do produto - êsse incentivo favorece mais a exportação de artigos não essenciais.

No caso do ICM, como as firmas não podem transferir o seu crédito fiscal para outras emprêsas, não há estímulo para que as emprêsas destinem sua produção exclusivamente, ou em maior parte, à exportação.
0 drawback tende a beneficiar mais as emprêsas estrangeiras, pois estas podem, em vários casos, importar bens intermediários da matriz ou emprêsas associadas.

De um modo geral, os incentivos fiscais criam condições para que a indústria nacional possa concorrer no mercado internacional. Não são, todavia, 
suficientes para superar a inércia dos exportadores em potencial.

\subsection{Incentivos financeiros}

Os incentivos financeiros funcionam como lubrificantes do processo de exportação. Os seus efeitos concentram-se, quase que exclusivamente, sôbre as seguintes variáveis: insumos, produção e preços. Com relação à primeira variável, o papel dêsses incentivos é oferecer às emprêsas capital de giro a baixo custo ${ }^{3}$ numa economia inflacionária, na qual a oferta de capital é extremamente limitada.

O efeito sôbre a promoção consiste, bàsicamente, em as firmas poderem oferecer crédito juntamente com o seu produto no exterior.

Como as taxas de juro no exterior variam com freqüência, as taxas internas devem ser reajustadas perioddicamente, de modo a manter a eficácia dos incentivos financeiros. Se, por exemplo, há uma redução das taxas no mercado financeiro externo, os exportadores brasileiros ficariam em desvantagem com relação à situação anterior, se as taxas que lhe são cobradas internamente não fôssem igualmente reduzidas.

A diferença fundamental entre os efeitos dos incentivos fiscais e financeiros é que os financeiros têm um efeito intenso nos insumos, e nulo na distribuição.

\subsection{Outros incentivos}

Esta categoria atua, essencialmente, sôbre a demanda externa através das variáveis promoção e distribuição. A única exceção é o incentivo para exportações em zonas de fronteira (item 3 ), o qual afeta, exclusivamente, a produção e os preços.

A política das emprêsas com relação ao produto não tem recebido influência dos incentivos governamentais. Estes poderiam favorecer a pesquisa, com vistas à adaptação dos produtos às preferências e condições externas, bem como ao desenvolvimento de novos produtos, e à análise da demanda estrangeira.

Quanto à promoção, os incentivos têm sido razoàvelmente eficazes no tocante ao suprimento de informações. $O$ Govêrno parece acreditar que, sendo competitivos os preços das mercadorias destinadas à exportação, informar é suficiente para garantir a realização de negócios. No entanto há atritos no mercado internacional. Fatôres como a separação geográfica, hiatos culturais, inércia empresarial e obstáculos burocráticos, impedem que as fôrças da oferta e procura atuem livremente. E verdade que 0 Govêrno tem promovido amplamente a participação do Brasil em feiras e exposições internacionais. Não tem atuado, porém, no campo de

propaganda e contatos de venda, talvez sob o pressuposto de que essas atividades se encontram no santuário da iniciativa privada.

Pode-se favorecer a distribuição das exportações de duas maneiras: facilitando a realização de transação em si e desenvolvendo o fluxo de mercadorias. Quanto à primeira, a permissão para exportações em consignação e a simplificação das formalidades burocráticas têm sido medidas de efeitos consideráveis. No entanto, a segunda maneira de melhorar a distribuição carece de maior atenção. Em particular, recomenda-se a melhoria do nosso sistema de transportes, inclusive instalações portuárias, tornando os portos capazes de operar com eficiência e a baixo custo.

\section{REAÇŌES DAS EMPRESAS}

A nossa análise mostrou que os incentivos fiscais e financeiros elevaram, significativamente, a lucratividade das exportaçōes de manufaturados. Esses e os demais incentivos não parecem, entretanto, suficientes para promover as exportações das emprêsas exclusivamente brasileiras, devido aos atritos citados. São as emprêsas estrangeiras as mais capazes de aproveitarem os incentivos, pois já dispõem, em geral, de uma estrutura de comercialização montada no comércio

internacional.

Para confirmar nossas hipóteses, realizamos uma série de entrevistas informais com executivos de emprêsas nacionais e estrangeiras. Os resultados são apresentados a seguir.

\subsection{Emprêsas estrangeiras}

Os incentivos foram recebidos com entusiasmo pela grande maioria das emprêsas entrevistadas. Sua aprovação manifestou-se em expressões como "solução inteligente para os problemas das exportações e desenvolvimento econômico", "os incentivos eliminam distorções", "o passo certo na direção certa". .. No entanto, à pergunta "sem os incentivos, os senhores continuariam a exportar?" foram dados três tipos de resposta. Um grupo (aproximadamente $50 \%$ das firmas entrevistadas) declarou que seu objetivo era o mercado interno, sendo o seu programa de exportações um resultado direto dos incentivos. Admitia, todavia, a possibilidade de criar um centro de exportação para a América Latina, com 0 desenvolvimento da ALALC.

Um segundo grupo (30\%), que em geral exportava bastante, continuaria a exportar se os incentivos fôssem abolidos, por diversas razões: algumas emprêsas, porque operam sob um acôrdo de complementação da ALALC; outras, porque as

- No caso do incentivo n.o 1, a taxa real chega mesmo a ser negativa, isto 6 , a taxa nominal é menor do que a de inflaçăo. 
matrizes as consideravam. centros de produção para um produto específico; outras, porque são persuadidas a exportar por meio do Govêrno. Finalmente, os restantes. $20 \%$ das firmas não estavam exportando, por uma das seguintes razões: a) os incentivos não chegavam a compensar 0 alto custo dos insumos e/ou sua baixa qualidade; b) os seus produtos não eram do tipo exportável; c) a matriz considerava outros centros de produção mais apropriados para a exportação, possivelmente por oferecerem maior margem de lucro.

\subsection{Emprêsas nacionais}

A atitude prevalecente entre os empresários é a de que a campanha na imprensa sôbre os incentivos gera o interêsse de ingressar no comércio de exportação. Mas essa disposição não é suficiente. Uma reação comum é a seguinte: "Agora, podemos concorrer em têrmos de preço, mas onde, a quem, o que e quando vamos vender?" Há preocupações com os problemas de adaptação do produto, trâmites burocráticos e a seleção de bons

intermediários. Enquanto o desenvolvimento dos incentivos, particularmente os de ordem fiscal, resultou num imediato fluxo de exportação para as emprêsas com uma rêde internacional de distribuição, as que não dispunham dessa vantagem (a maior parte, brasileiras) conseguiram, quando muito, resultados insignificantes e com produtos tradicionais (produtos alimentares, calçados, pedras lapidadas, etc.). Outra queixa se referia à qualidade dos insumos industriais: a isenção de tarifas aduaneiras só se aplica aos bens de capital sem similar nacional.

\section{UMA SOLUÇAO: UMA COMPANHIA DE EXPORTAÇAO}

A análise do item 4 e o apanhado de opiniões empresariais evidenciaram falhas consideráveis no atual sistema de incentivos às exportações de manufaturados. Dois aspectos adicionais merecem destaque.

Em primeiro lugar, como os incentivos beneficiam em geral apenas emprêsas industriais e não as firmas dedicadas exclusivamente ao comércio de exportação, o sistema não estimula o estabelecimento de emprêsas puramente exportadoras, as quais, na ausência da solução que se vai propor, teriam uma contribuição considerável a dar ao incremento das exportações.

Outro aspecto de capital importância refere-se à possibilidade de outros países virem a eliminar as vantagens proporcionadas pelos incentivos às emprêsas brasileiras, concedendo benefícios similares às suas próprias emprêsas. É de se esperar, portanto, que, a longo prazo, o nosso País só consiga exportar os manufaturados que possa produzir a custos mais baixos que os concorrentes estrangeiros, de acôrdo com 0 princípio clássico das "vantagens comparativas".

Em face das deficiências do atual sistema de incentivos e tendo em vista as considerações dos dois parágrafos anteriores, acreditamos na conveniência da criação de uma companhia brasileira de exportação na forma que passamos a descrever.

- capital da Companhia de Exportação será financiado (participação acionária e empréstimos), em sua maior parte, com recursos governamentais. Com o tempo, as ações do Govêrno poderiam ser transferidas para os empregados das emprêsas e para 0 público em geral. 0 contrôle governamental na etapa inicial justifica-se pela amplitude do empreendimento e pela dificuldade de captar recursos privados para uma emprêsa de rentabilidade aleatória. 
A companhia procurará desenvolver as exportações de manufaturados através de uma promoção ativa. $`$ Ela consistiria essencialmente, nas seguintes atividades: a) informar, com precisão, as emprêsas brasileiras sôbre suas oportunidades comerciais em outros países; b) assessorar as emprêsas em todos os aspectos relacionados com o processo de exportação e a produção para a exportação; c) realizar, ela mesma, exportações nos casos em que as emprêsas isoladas não sejam capazes de fazê-lo.

Propomos para a companhia de exportação a seguinte estrutura: os acionistas delegarão podêres a um presidente, que supervisionará três vice-presidentes, os quais serão os diretores da Rêde Interna, Rêde Externa e Departamento de Projetos Especiais.
ORGANOGRAMA DA COMPANHIA DE EXPORTAÇAO

\begin{tabular}{|l|c|c|}
\hline \multicolumn{3}{|c|}{ Acionistas } \\
\hline $\begin{array}{l}\text { Emprêsas } \\
\text { privadas }\end{array}$ & Público & \multirow{2}{*}{ Govêrno } \\
\cline { 2 - 2 } & Empregados & \\
\hline
\end{tabular}
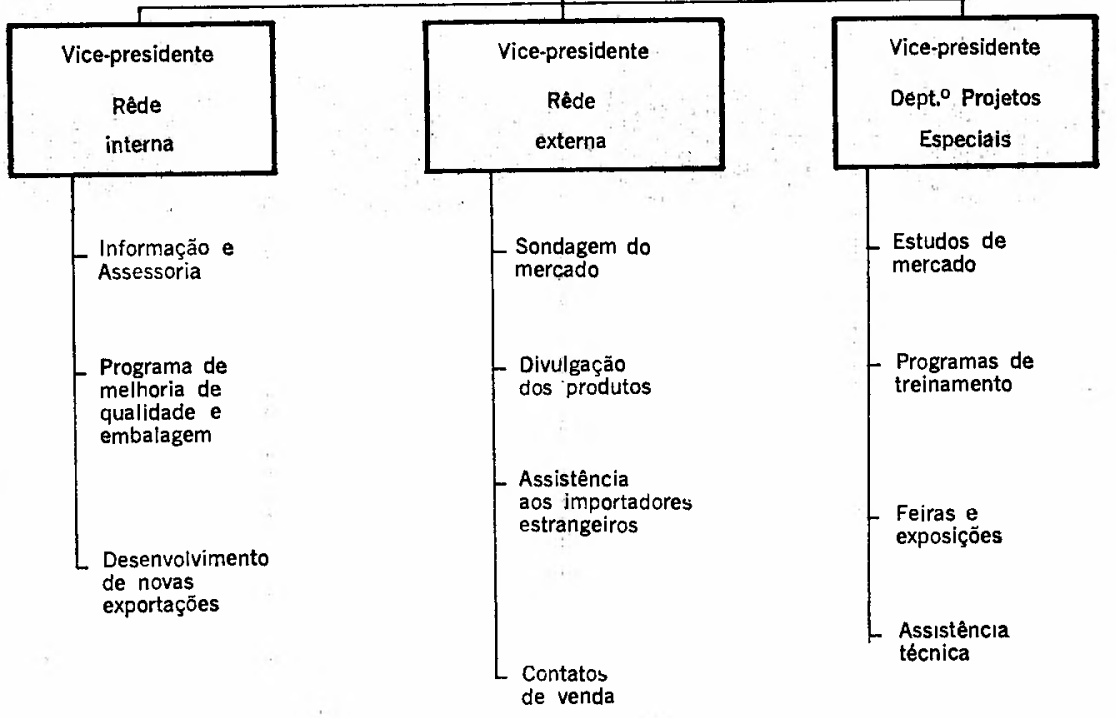

A rêde interna consistirá num conjunto de escritórios espalhados por todo o País, os quais manterão contato permanente com as emprêsas exportadoras, prestando-Ihes informações e assessoria. Êsses escritórios também implementarão programas de melhoria de qualidade $e$ embalagem, bem como de desenvolvimento de novas exportações. A rêde externa, por sua vez, procurará criar novos canais de distribuição para os nossos produtos nos mercados existentes e em potencial. Disporá de escritórios comerciais farão uma sondagem permanente do mercado, divulgarão os produtos brasileiros, prestarão assistência aos importadores e, o que é fundamental, funcionarão como ponto para a realização de negócios. 0 departamento de projetos em diversos paises, ${ }^{5}$ os quais especiais teria a seu cargo atividades diversas como estudos de mercado, programas de treinamento, organização de feiras e exposições, propaganda, assistência técnica, etc. Esse departamento atuaria ora em cooperação com as rêdes interna e externa, ora isoladamente.

O sucesso da companhia de exportação dependerá da dedicação e capacidade dos diretores e de seu pessoal. Para criar motivação, recomenda-se o sistema de participação dos empregados nos lucros da emprêsa. Por outro lado, a seleção de pessoal, principalmente de especialistas em comércio exterior, deverá ser extremamente criteriosa. Além disso, a companhia deverá promover o aprimoramento contínuo de seus técnicos no Pais e no exterior.

Evidentemente, os detalhes da organização de um empreendimento de tão elevadas proporções não poderiam ser dados num artigo como êste. $O$ nosso objetivo foi apenas descrevê-lo em linhas muito gerais.

Finalizando, gostaríamos de frisar que não se deve enxergar, na idéia de criação da companhia de exportação, uma ameaça à iniciativa privada no comércio exportador. 0 seu objetivo deve ser auxiliar e complementar a atuação das emprêsas particulares; jamais procurar substituí-las.

\footnotetext{
- Foram criadas, em 1970, duas emprésas de promoção de exportaçöes: a Companhia de Promoção de Exportações de Manufaturados do Estado de São Paulo (COPEME) a Promo-Export (na área da SUDENE). Evidentemente, estas emprésas teriam que atuar em consonância com a companhia de âmbito nacional aqui sugerida.

- Os atuais escritórios comerciais do Ministério das Relaçðes Exteriores seriam integrados na nova estrutura.
} 